\title{
Gastroesophageal reflux disease in India: ISG Task Force completes a task!
}

\author{
Gourdas Choudhuri • Philip Abraham
}

Received: 13 July 2011 / Accepted: 13 July 2011 / Published online: 27 July 2011

(C) Indian Society of Gastroenterology 2011

The article "Epidemiology and symptom profile of gastroesophageal reflux in the Indian population"[1] in this issue of the Journal marks a milestone in recognizing, facing and studying a common gastrointestinal (GI) disorder as it occurs in India, through a national collaborative effort.

Although gastroesophageal reflux disease (GERD) has been perceived by Indian gastroenterologists to be common in clinical practice, and a few articles from India had sporadically reported on certain of its facets, India stood out as one of the countries lacking national data on its prevalence, features and severity. The presence of three vibrant national societies, two indexed journals and 1,700 experts dealing with digestive disorders in this country added to the irony.

The concept of creating a "task force" within the Indian Society of Gastroenterology to study and document the frequency and features of common digestive disorders as they occur in India was conceived in 2003. After much brainstorming by enthusiasts and skeptics, two such ventures, one on irritable bowel syndrome and the other on GERD, rolled out in 2004. The findings of the IBS task force have already appeared in the pages of this Journal [2].

The challenges of conceiving, creating, propelling and wrapping up the task force posed unique challenges. The greatest gamble was appointing a coordinator who would be the right mix of youth and seniority, knowledge and wisdom, passion and discretion, energy and stability, and

\section{G. Choudhuri $(\bowtie)$}

Department of Gastroenterology, Sanjay Gandhi Postgradute

Institute of Medical Sciences,

Lucknow 226 014, India

e-mail: choudhuri.gour@gmail.com

\section{P. Abraham}

Division of Gastroenterology, P D Hinduja National Hospital and

Medical Research Center, Veer Savarkar Marg,

Mumbai 400 016, India firmness with acceptability, to drive the activity. Dr Shobna Bhatia proved well suited for the job.

The activity started with invitation to gastroenterologists from across the country to join in. The core group, guided by seniors, tried to ensure that the data were representative of the large nation with its multiple regional variations of ethnicity, diet, and habits. Also, efforts were made to eliminate a biased inclusion of serious cases by including data only from large hospitals; indeed doctors in individual practice were invited to keep the balance.

Further, an activity of this enormity required funds, manpower resources and frequent effective communication. Zydus Alidac, Ahmedabad, India played the crucial supportive role and proved an example of industry-academia partnership.

The reporting of the findings of the task force should be of interest not just to Indian doctors but to researchers across the globe. Over the last few years, the task force has received guidance and inputs from several international stalwarts, one of whom has written an editorial in this issue [3]. Further, the flurry of activity of the task force has renewed research interest on this topic as can be seen from three other articles on the topic in this issue.

Where do we go from here? The successful outcome of this venture has vindicated the belief that Indian doctors can engage in academic team-work to address national health issues. It has in turn posed new challenges to explore the reasons behind the new findings that the report throws up. Why do Indian patients suffer less often from severe GERD? Is there something in the Indian diet that protects? What is the causal relationship with the virtually ubiquitous H. pylori? And of economic concern are questions such as: Do most patients with GERD symptoms benefit from endoscopy? Can lower doses of acid suppressants be as effective in Indian patients as they have smaller body surface area? Are lifestyle and diet changes worthy of study, 
a field largely neglected due to the pharmaceutical industry's lack of interest in this competing approach?

Indian Society of Gastroenterology has come of age, and seems poised to make significant research contributions on common GI disorders. It has demonstrated that team-work is the best way forward.

Gourdas Choudhuri (Hon Secretary of ISG, 2002-08, President of ISG, 2009-10)

Philip Abraham (President of ISG, 2002-03)

\section{References}

1. Bhatia SJ, Reddy DN, Ghoshal UC, et al. Epidemiology and symptom profile of gastroesophageal reflux in the Indian population: Report of the Indian Society of Gastroenterology Task Force. Indian J Gastroenterol. 2011;30. doi:10.1007/s12664-011-0112.

2. Ghoshal UC, Abraham P, Bhatt C, et al. Epidemiological and clinical profile of irritable bowel syndrome in India: Report of the Indian Society of Gastroenterology Task Force. Indian J Gastroenterol. 2008;27:22-8.

3. Gaddam S, Sharma P. Shedding light on the epidemiology of gastroesophageal reflux disease in India-a big step forward. Indian J Gastroenterol. 2011;30. doi:10.1007/s12664-011-0108-6. 